PROC. OF JSCE,

No. 242, OCT. 1975

\title{
EFFECTS OF STRESS-STRAIN CONDITIONS ON DYNAMIC PROPERTIES OF SANDS
}

\author{
By Eiichi KURIBAYASHI ${ }^{*}$, Toshio IWASAKI ${ }^{* *}$ and Fumio TATSUOKA ${ }^{* * *}$
}

\section{INTRODUCTION}

In analyzing seismic behavior of soil deposits and studying soil-structure interaction problems, it is essential to evaluate dynamic properties of soils. For this purpose, in situ measurements of elastic waves and various laboratory tests using simple shear apparatus, triaxial apparatus or resonant-column apparatus have been conducted by many investigators. It is already known that dynamic properties of soils such as shear moduli and damping characteristics might depend upon stress conditions, shear strain amplitudes, strain histories, void ratios, saturation, particle characteristics, inner structures of soils, etc. To clarify the relationship between dynamic properties of soils and those parameters, the authors have been conducted extensive resonant-column tests on dry and saturated specimens of various sandy soils. This paper describes the instrumentation employped and some results obtained from the resonant column testing.

\section{APPARATUS}

A resonont column procedure for soil was initiated by lida $^{1}$ ) and the procedures are fully

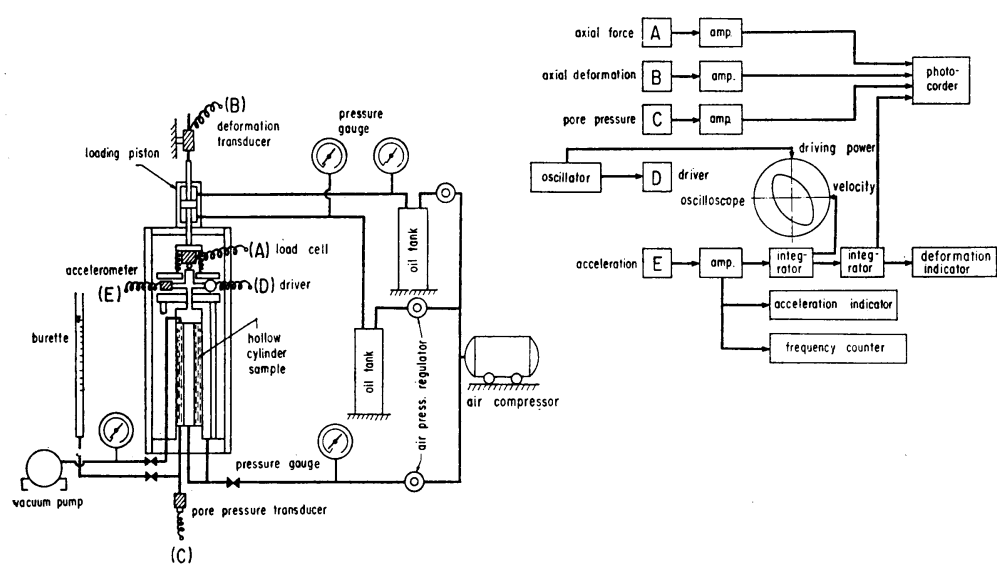

Fig. 1 Schematic diagram of the apparatus.

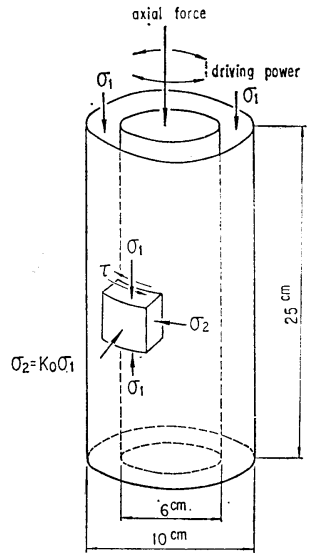

Fig. 2 Stress condition of Sample.
* M. Eng., Chief, Earthquake Engineering Research Section, Public Works Research Institute, Ministry of Construction.

** M. S., Chief, Civil Engineering Section, International Institute of Seismology and Earthquake Engineering, Building Research Institute, Ministry of Construction.

*** Dr. Eng., Research Engineer, Earthquake Engineering Research Section, Public Works Research Institute, Ministry of Construction. described in the textbook authored by Richart, Hall and Woods ${ }^{2}$. A precise equipment which is able to control the stress conditions and the magnitude of shear strain was developed by Hardin and Music $^{3)}$. A more reliable apparatus was developed by Drnevich ${ }^{4}$, where a hollow cylindrical specimen can be equipped. The samples of Drnevich-type apparatus are $30-\mathrm{cm}$ long, $4-\mathrm{cm}$ inside diameter, and either $1-\mathrm{cm}$ or $0.5-\mathrm{cm}$ in wall thickness depending on the grain size of the sandy material tested. The principal of ap- 
paratus employed for the present study is similar to Drnevich-type apparatus. The schematic diagram is shown in Fig. 1. Fig. 2 shows the stress condition acting on a sample. The hollow cylindrical specimens tested are $25-\mathrm{cm}$ in height, $10-\mathrm{cm}$ in outside diameter and $6-\mathrm{cm}$ in inside diameter. This arrangement permits a more uniform shear deformation in a section of samples. The specimens are fixed at the bottom and the oscillators which supply the system with the torsional vibratory force are fastened to the rigid mass on the top of the specimen. The confining pressure equally applied to the outside and inside of specimens is supplied by air pressure and the axial load can be applied independently of the confining pressure. Accordingly, the anisotropic stress condition similar to the $K_{0}$-stress condition in the horizontal ground can be produced.

The quantities measured during a steady state vibration test are resonant frequency of the oscillator-specimen system, vibration amplitude at the top of the specimen, length change and volume change in the specimen, confining pressure and axial load. Furthermore, amplitude time decay curves are recorded after shutting off the driving power at the resonance. From these measurements, the shear strain amplitudes, the shear moduli and the logarithmic decrements can be evaluated for the testing materials.

\section{PRINCIPLE OF TESTING}

\subsection{Shear strain amplitude}

Shear strain $\gamma$ in the sample is expressed as

$$
r=\frac{\partial u}{\partial x}=\frac{\partial r \theta}{\partial x} \quad \text { (rad.) }
$$

where $u(x, t)$ is the displacement, $\theta(x, t)$ is the angular displacement in radian, $x$ is the axial coordinate and $r$ is the radial coordinate. The configuration of the specimen with a large mass at the top produces linear deformation and accordingly permits uniform shear strain condition over the entire length of the specimen. Furthermore, an average shear strain in a horizontal section would be expressed by the value at $4-\mathrm{cm}$ in radius. Accordingly, shear strain in the specimen is represented as

$$
\gamma=\frac{4}{l} \theta_{t} \quad(\mathrm{rad} .)
$$

where $l$ is the length of specimen $(\mathrm{cm})$ and $\theta_{t}$ is the angular displacement at the top of the specimen.

\subsection{Shear modulus}

The shear stress-strain curves of sandy specimens subjected to cyclic loads have a property shown in Fig. 3. In case of the hysteretic damping such as that of sands, the linear approximation could be used to simply simulate its dissipative nature. Let the material constants of sands define as

$G$ : equivalent shear modulus,

$\eta \quad$ : hysteretic damping coefficient $t^{5)}=\frac{\Delta W}{2 \pi W}$,

$W:$ strain energy as shown in Fig. 3 and

$\Delta W:$ damping energy as shown in Fig. 3.

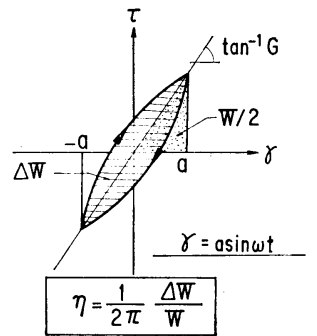

Fig. 3 Stress-strain curve of sands.

For a equivalent linear isotropic material having the same values as the above $G$ and $\eta$, a more useful formation is that of a complex modulus. Denoting that $\boldsymbol{\tau}$ and $\boldsymbol{\gamma}$ are shear stress and strain in complex notation, respectively and $G$ and $G^{\prime}$ are complex shear moduli of the equivalent linear isotropic material, the stress-strain relation is expressed as

$$
\tau=\left(G+i G^{\prime}\right) \gamma
$$

Then, its hysteretic damping coefficient $\eta$ could be related with complex shear moduli $G$ and $G^{\prime}$ as

$$
\eta=\frac{G^{\prime}}{2 G}
$$

On the other hand, the wave propagation equation for the shear deformation of the continuous medium will be

$$
\rho \frac{\partial^{2} u}{\partial t^{2}}=\frac{\partial \tau}{\partial x}
$$

where $\rho$ is the density and $\boldsymbol{u}$ is the displacement in the orthogonal to propagation direction. Then, replacing equations (1), (3) and (4) into equation (5), the wave equation for the equivalent linear isotropic material in resonant-column tests is expressed as 


$$
\rho \frac{\partial^{2} \theta}{\partial t^{2}}=G(1+i \cdot 2 \eta) \frac{\partial^{2} \theta}{\partial x^{2}}
$$

where $\theta$ is the angular displacement in radian in complex notation. An analytical solution of this equation was obtained by the previous investigators $^{2), 3)}$. In a steady vibration state, shear modulus $G$ is a complicate function of the density and the dimensions of the sample, the apparatus constants and the resonant frequency. The value of $G$ was evaluated by an iteration method by using an electronic computer.

\subsection{Damping coefficient}

By enforcing the system into the resonant state and then shutting off the driving power, logarithmic decrements $\Delta_{t}$ could be obtained. From the logarithmic decrements, hysteretic damping coefficients $\eta$ could be obtained independently of the sample's dimensions and its boundary conditions. For free vibration, a solution could be assumed as

$$
\boldsymbol{\theta}=\boldsymbol{A}(x) e^{\left(i \omega_{n}-\lambda\right) t}
$$

where $\boldsymbol{A}(x)$ is mode of deformation, $\omega_{n}$ is the natural circular frequency of the system and $\lambda$ is an attenuation factor with respect to time. Replacing equation (7) into equation (6),

$$
\lambda=\frac{\omega_{n}}{2 \eta}\left[-1+\sqrt{1+(2 \eta)^{2}}\right] \approx \omega_{n} \eta
$$

Then, the relation between logarithmic decrement $\Delta_{t}$ and hysteretic damping coefficient $\eta$ will be

$$
\Delta_{t}=\lambda \frac{2 \pi}{\omega_{n}} \approx 2 \pi \eta
$$

Using equation (9), hysteretic damping coefficient $\eta$ can be obtained from measured logarithmic decrement $\Delta_{t}$.

\section{TESTING PROCEDURES}

Physical properties of the materials tested are listed in Table 1 and their grain size distributions

Table 1 Physical properties of materials tested.

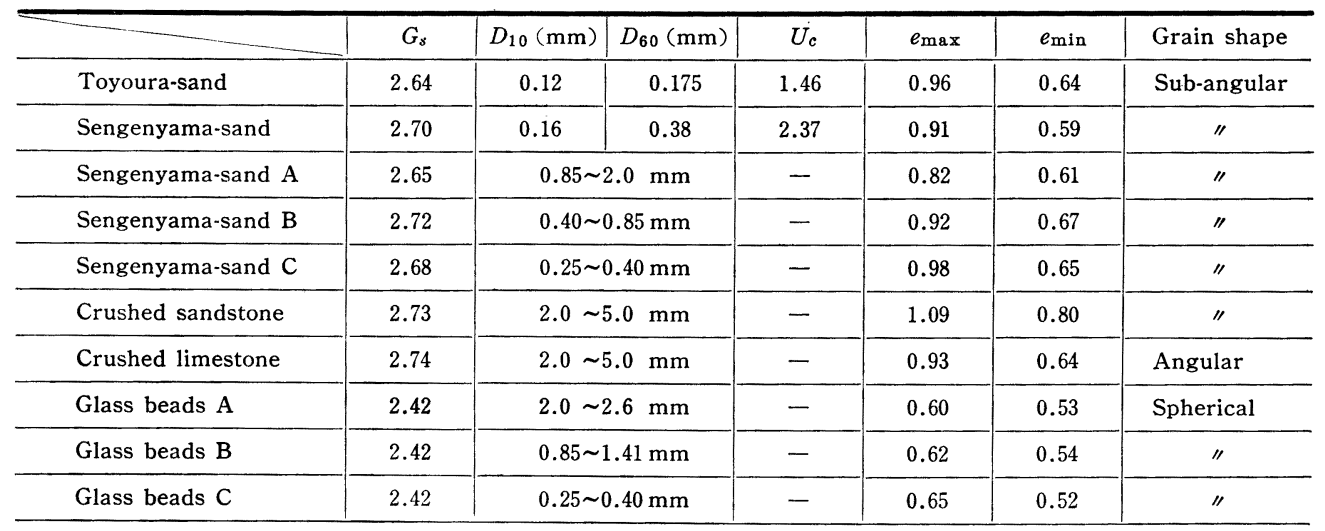

are shown in Fig. 4. Toyoura-sand has uniform grading and sub-angular particles. Sengenyamasand from Sengenyama area near Chiba, Japan has well-grading and also has sub-angular particles. This sand has diluvial origin and therefore includes some silty particles. Sengenyamasands $A, B$ and $C$ shown in Fig. 4 were prepared by sieving sands obtained from Sengenyama area. Crushed sandstone have angular particles and crushed limestone have sub-angular particles. Glass beads $A, B$ and $C$ have almost spherical forms. As shown before, test results on granular materials are discussed in this paper.

Resonant-column tests were conducted on samples having various void ratios. For Toyourasand, both air-dry and saturated samples were

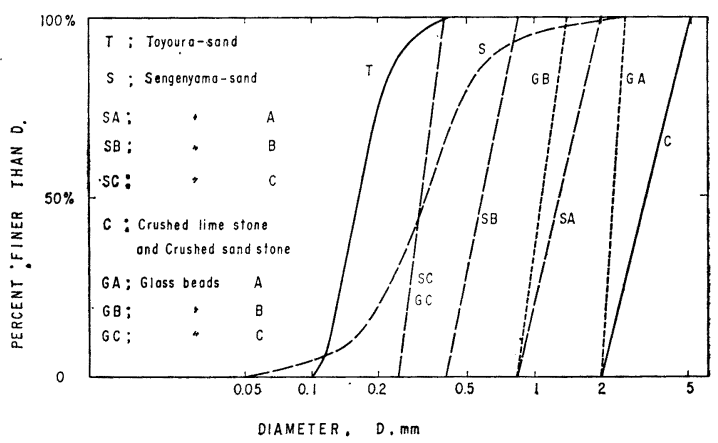

Fig. 4 Grain size distribution curves.

prepared and consolidated isotropically and anisotropically; namely, the stress ratios $\sigma_{1} / \sigma_{3}$ have 
values of 1.0 and 2.0 , respectively. For the other sands and glass beads, only air-dry specimens were tested and stress ratio $\sigma_{1} / \sigma_{3}$ was kept equal to 1.0. Saturated samples were prepared by spooning freshly boiled sands into a split mold filled with de-aired water. Air-dry samples were prepared by spooning air-dry sands into the mold. Densification of the samples was achieved by tapping the mold with a wooden hammer.

After the confining pressure and axial load were applied to the sample, the stress condition that is defined by $\sigma_{1}$ and $\sigma_{3}$ was kept constant and the vibratory shear strain amplitude was increased from about $5 \times 10^{-6}$ to about $2 \times 10^{-4}$. Both resonant frequency and logarithmic decrement were measured at various values of shear strain amplitudes. Next, another series of tests was achieved for different stress condition and the above mentioned procedure was repeated. Confining pressure varied from $0.20 \mathrm{~kg} / \mathrm{cm}^{2}$ to 6.0 $\mathrm{kg} / \mathrm{cm}^{2}$. In Fig. 5 one of test results using a

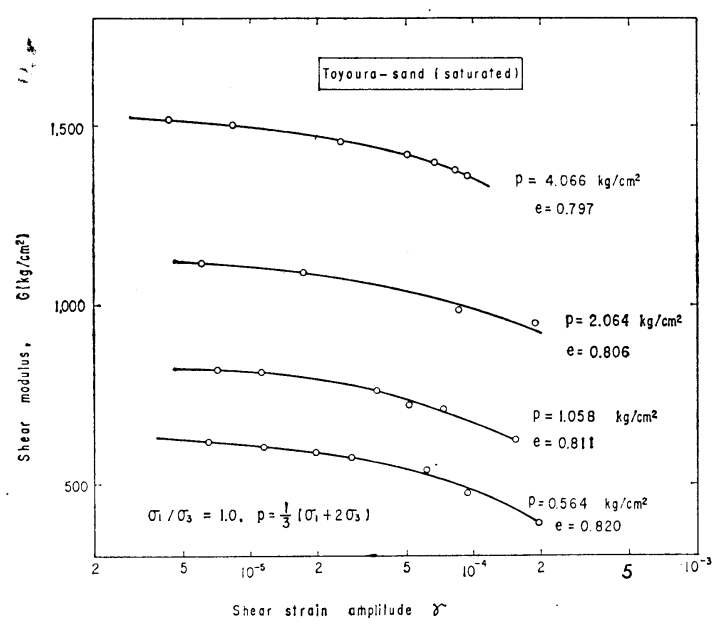

Fig. 5 Shear modulus versus shear strain amplitude of saturated Toyoura-sand.

Toyoura-sand sample is shown where $p$ is the mean principal stress equal to $\frac{1}{3}\left(\sigma_{1}+2 \sigma_{3}\right)$ and $e$ is the void ratio which changed slightly during consolidation. In one sample, it would be impossible to control all values of shear strain amplitude, stress condition and void ratio. Then, it is necessary to convert the measured values of $G$ into the values for predetermined values of $p$, $\gamma$ and $e$. Meanwhile, Hardin et al. ${ }^{8}$ ) showed the experimental equation for round Ottawa-sand for low strain amplitude as

$$
G=700 \frac{(2.17-e)^{2}}{1+e} p^{0.5}
$$

where $G$ is the shear modulus $\left(\mathrm{kg} / \mathrm{cm}^{2}\right), p$ is the mean principal stress $\left(\mathrm{kg} / \mathrm{cm}^{2}\right)$ and $e$ is the void ratio. Then, the values of $G$ for $\gamma=10^{-5}$ and $\gamma=10^{-4}$ were obtained from the curves in Fig. 5 and subsequently, using the postulate that $G$ is proportional to $(2.17-e)^{2} /(1+e)$ as shown by equation (10), the values of $G$ for the mean value of void ratios of tested sample, say $e=0.81$ in Fig. 5 , were obtained where the change in $G$ due to the change of void ratio in this procedure was on the order of a few percent. In the next, the values of $G$ and $p$ were plotted on full-log graph as shown in Fig. 6, then values of $G$ for $e=0.81$ for $p=0.5,1,2,3,4$ and $6 \mathrm{~kg} / \mathrm{cm}^{2}$ were obtained from the curves in Fig. 6.

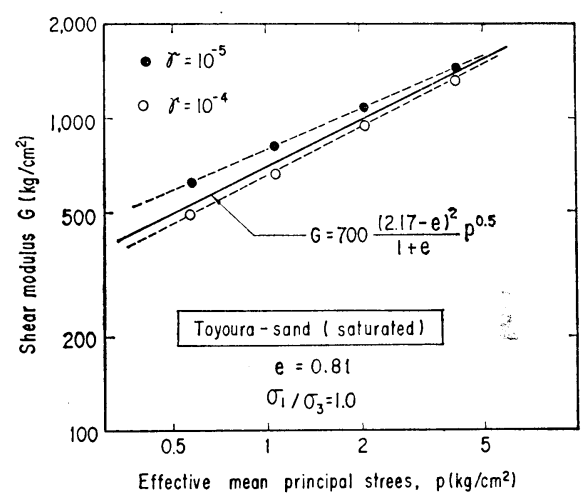

Fig. 6 Shear modulus versus mean principal stress of saturated Toyoura-sand.

\section{TEST RESULTS}

\subsection{Effects of mean principal stress on shear modulus}

As shown in Figs. 6 to 9, shear modulus varies

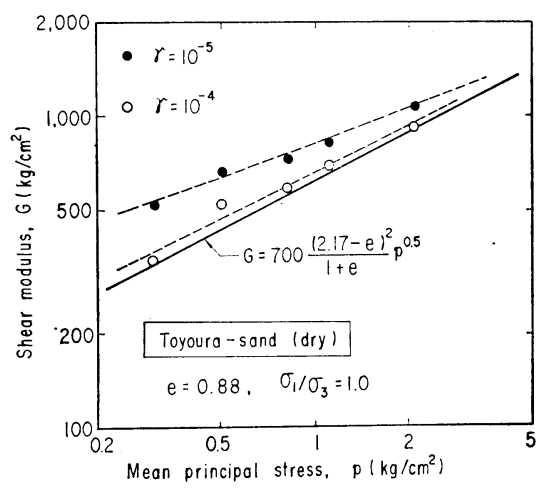

Fig. 7 Shear modulus versus mean principal stress of air-dry Toyoura-sand. 


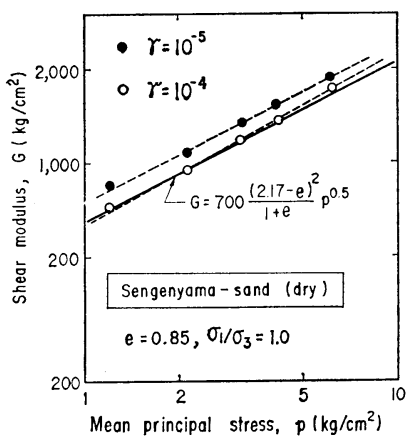

Fig. 8 Soear modulus versus mean principal stress of air-dry Sengenyama-sand.

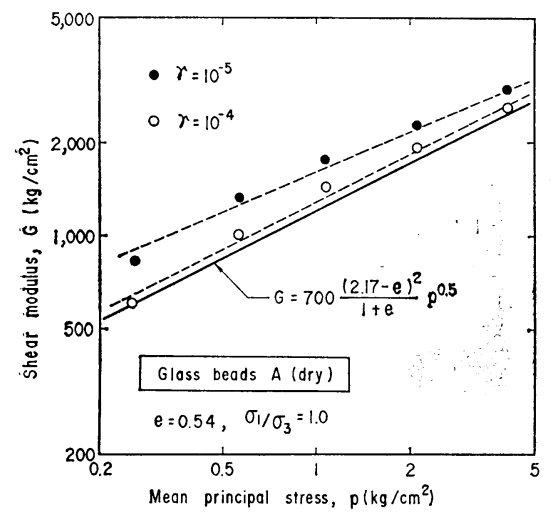

Fig. 9 Shear modulus versus mean principal stress of air-dry Glass-beads.

almost proportionally to the square root of mean principal stress provided that the other parameters keep constant. The relationship between shear modulus $G$ and mean principal stress $p=$ $\frac{1}{3}\left(\sigma_{1}+2 \sigma_{3}\right)$ could be represented by

$$
G=k p^{m}
$$

where $k$ is a constant. By observing these figures carefully, it is found that the values of $m$ increase slightly with increase in shear strain amplitude as shown in Figs. 10 (a) and (b) where the legends are the same as those in Figs. 18 (a) and (b). By these figures, the value of $m$ at $\gamma=10^{-4}$ could be estimated to be about 0.5 for all materials tested and $m$ at $\gamma=10^{-5}$ is about 0.44 . Furthermore, the value of $m$ at $\gamma=10^{-6}$ is obtained to be 0.38 by extrapolation.

\subsection{Effects of void ratio on shear modulus}

All data obtained are summarized in Fig. 11 where shear moduli and void ratios are plotted
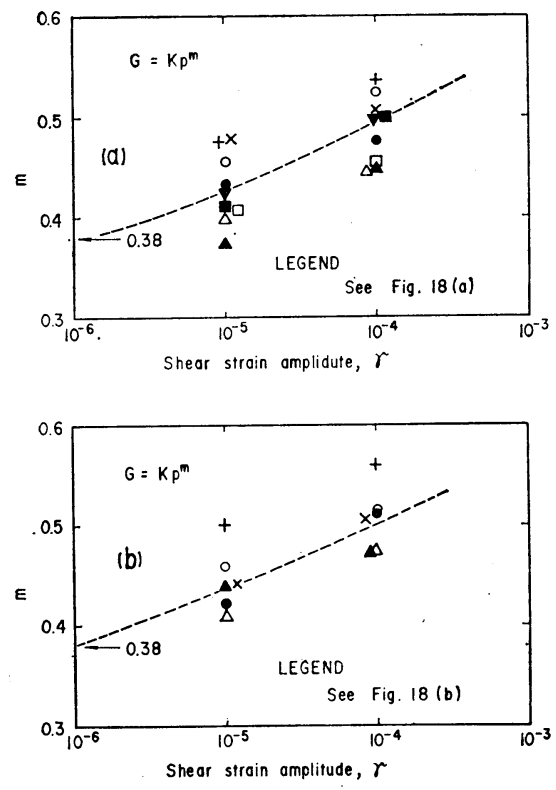

Fig. $10 m$ versus shear strain amplitude.

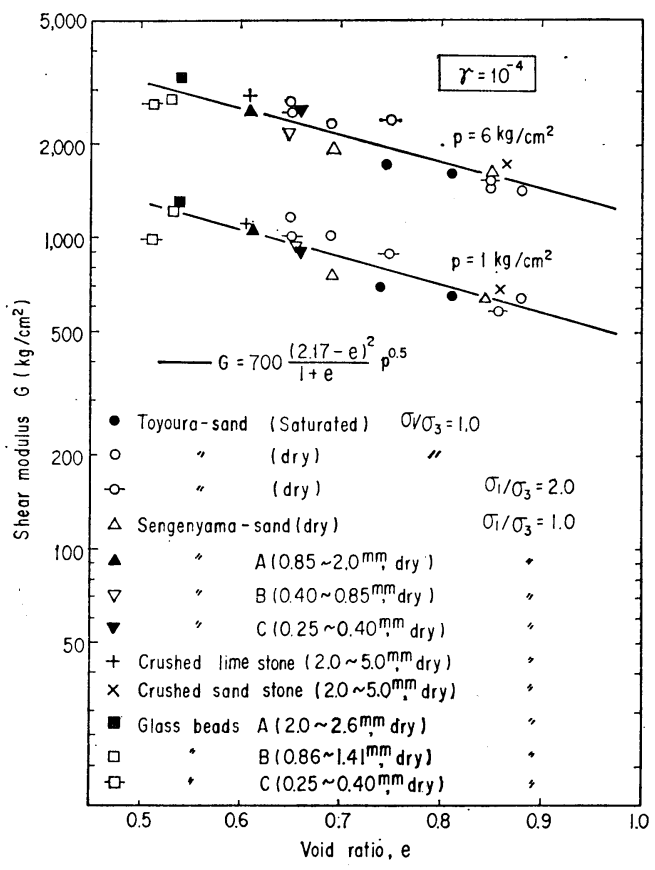

Fig. 11 Shear modulus versus void ratio of all materials tested.

on a semilog graph for two cases: $p=1 \mathrm{~kg} / \mathrm{cm}^{2}$, $\gamma=10^{-4}$ and $p=6 \mathrm{~kg} / \mathrm{cm}^{2}, \gamma=10^{-4}$. As denoted in Fig. 11, it is found that all data obtained almost agree with equation (10) for $\gamma=10^{-4}$ in the range 
of $\sigma_{1} / \sigma_{3}=1 \sim 2$ irrespectively of roundness of particles, grading and kinds of materials used in these tests. It would be of interest that shear moduli of various granular materials are not dependent on relative density $\mathrm{Dr}$, but on void ratio $e$.

\subsection{Effects of stress ratio on shear modulus and damping coefficient}

As shown in Fig. 11, shear moduli of anisotropically consolidated air-dry Toyoura-sand under $\sigma_{1} / \sigma_{3}=2.0$ agree with those of isotropically consolidated air-dry Toyoura-sand. To investigate the effects of stress ratio on shear modulus in a wider range of stress ratio, particular tests were conducted where stress ratio was increased and then decreased under constant value of $p$. Some of the test results are shown in Figs. 12 to 14, where stress ratio is denoted by

$$
\frac{p}{q}=\frac{\sigma_{a}-\sigma_{r}}{\frac{1}{3}\left(\sigma_{a}+2 \sigma_{r}\right)}=\frac{\sigma_{1}-\sigma_{3}}{\frac{1}{3}\left(\sigma_{1}+2 \sigma_{3}\right)}
$$

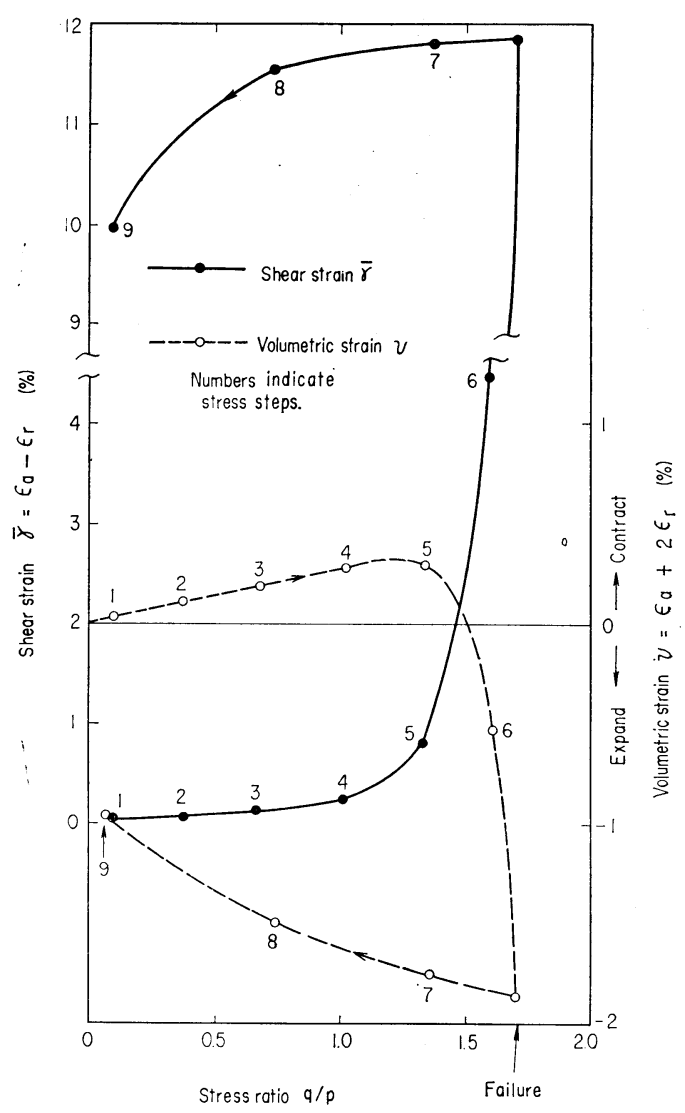

Fig. 12 Shear and volumetric strains versus stress ratio.

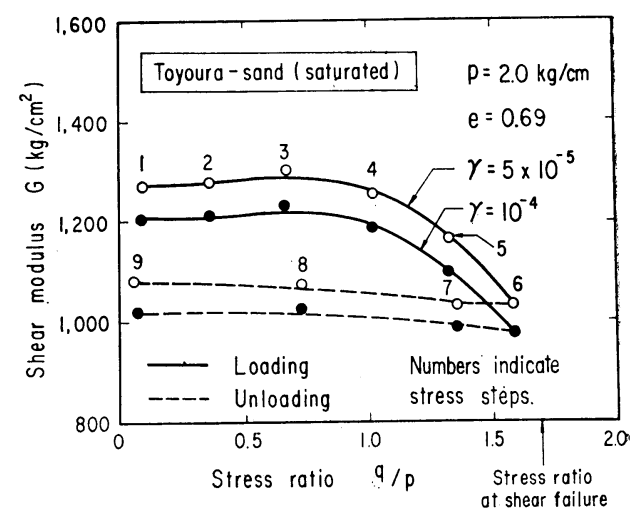

Fig. 13 Shear modulus versus stress ratio of saturated Toyoura-sand.

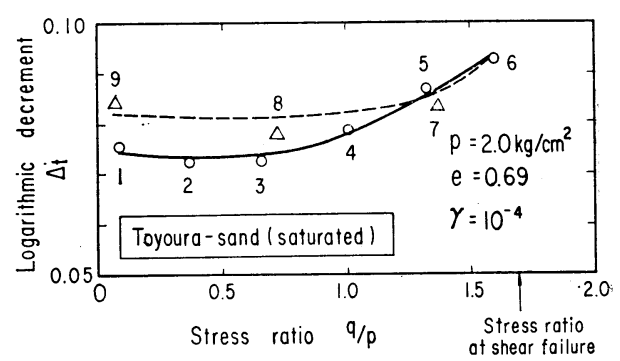

Fig. 14 Logarithmic decrement versus stress ratio of saturated Toyoura-sand.

where $\sigma_{a}$ and $\sigma_{r}$ mean the axial and radial stresses, respectively and $q$ is $\sigma_{a}-\sigma_{r}$. As the value of $p^{n}$ was not constant precisely and varied between 2.047 and $2.205 \mathrm{~kg} / \mathrm{cm}^{2}$ and the volume of the specimen varied due to dilatancy during shear deformation as shown in Fig. 12, shear moduli. for $p=2.0 \mathrm{~kg} / \mathrm{cm}^{2}$ and $e=0.69$ were obtained by modifying the measured values by using equation (10). On the other hand, logarithmic decrements in Fig. 14 are measured ones as its change with $p$ and $e$ is smaller than shear moduli. In Figs. 13 and 14, it is shown that shear moduli and logarithmic decrements take nearly constant values irrespectively of the variation of stress ratio $q / p$ up to $q / p$ of a certain value, say 1.0 (i.e., $\left.\sigma_{1} / \sigma_{3}=2.5\right)$. This has been indicated already by Hardin and Black ${ }^{7}$. It would be noted that shear strain $\bar{\gamma}=\varepsilon_{a}-\varepsilon_{r}$ where $\varepsilon_{a}$ and $\varepsilon_{r}$ mean axial and radial strains, respectively, begins to increase abruptly and dilatancy of specimen starts at this stress ratio as shown in Fig. 12. However, beyond this value of stress ratio, shear moduli begin to decrease and logarithmic decrements begin to increase with increase in stress ratio. Furthermore, it is found that even after unloading shear 
modulus is smaller and logarithmic decrement is larger than those before shearing. Similar results are obtained also for other $p$-constant test. These phenomena would be due to the anisotropic inner structure in specimen which was caused by shearing of the specimen.

\subsection{Effects of shear strain amplitude on shear modulus}

Because of the nonlinear characteristics of stress-strain relationship of soils, shear moduli would decrease with increasing shear strain amplitude. So far, some curves representing the $G-\gamma$ relationship such as that by Seed and Idriss $^{8)}$ have been proposed. Meanwhile, effects of shear strain amplitude on shear modulus increase with decrease in mean principal stress $p$. This could be supposed from Figs. 6 to 9 where the ratio of shear modulus at $\gamma=10^{-5}$ to that at $\gamma=10^{-4}$ gets larger with decrease in $p$. Fig. 15 shows the effects of mean principal stress on $G-\gamma$ relations, where the abscissa is shear strain amplitude in log-scale and the ordinate is the ratio of shear modulus $G$ to that at $\gamma=$

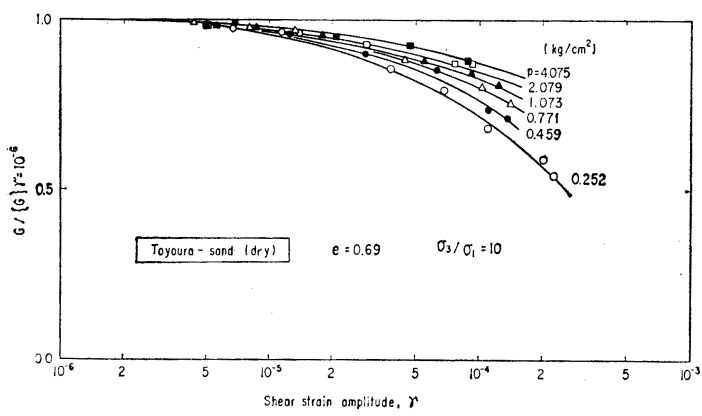

Fig. 15 Decreasing rate of shear modulus with increase in shear strain amplitude of air-dry Toyoura-sand.

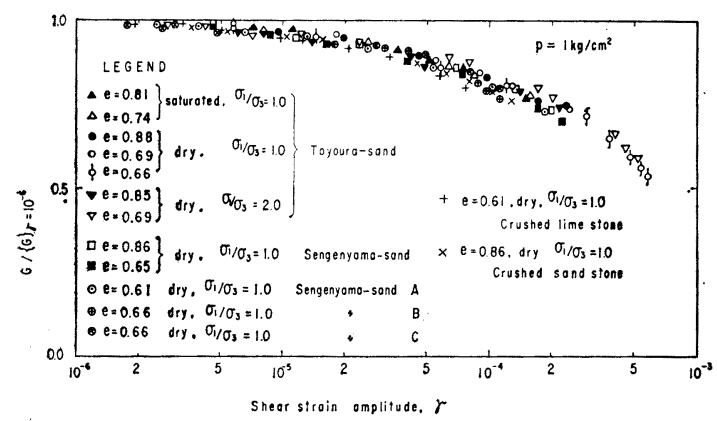

Fig. 16 Decreasing rate of shear modulus with increase in shear strain amplitude for $p=1 \mathrm{~kg} / \mathrm{cm}^{2}$.

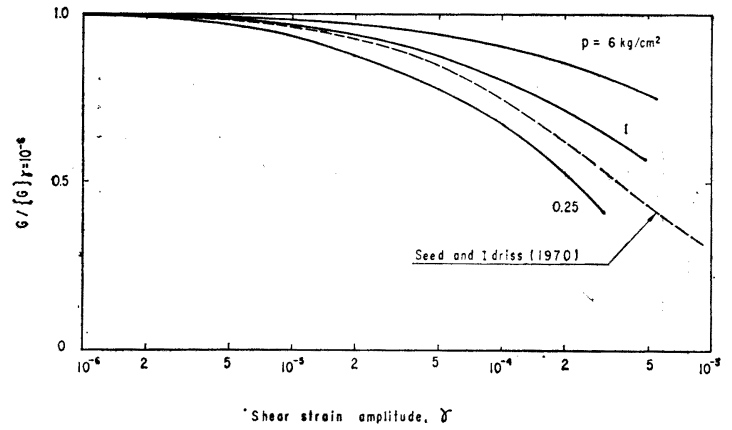

Fig. 17 Mean decreasing ratio of shear modulus with increasing in shear trains amplitude.

$10^{-6}, G /\{G\}_{\gamma=10^{-6}}$. Furthermore, Fig. 16 shows that

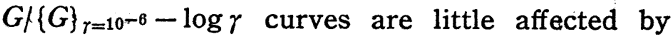
change in void ratios, stress ratios and kinds of sands for cases of materials tested. Fig. 17 shows average curves for various mean principal stress obtained by the procedure shown in Fig. 16. From this figure, it is found that the variation of shear moduli with shear strain amplitude would be smaller than that proposed by Seed and Idriss ${ }^{8}$ when $p$ has a value larger than about $0.5 \mathrm{~kg} / \mathrm{cm}^{2}$.

\subsection{Shear modulus at $\boldsymbol{\gamma}=10^{-6}$}

The shearing strain amplitude generated in subgrounds during in-situ measurements of elastic waves is on the order of around $10^{-6}$ or less. To compare shear moduli obtained from those in-situ measurements with those from resonant-column tests, the relationship between shear modulus at $\gamma=10^{-6}$ and the mean principal stress and the void ratio in resonant-column tests would be necessary. However, shear modulus at $\gamma=10^{-6}$ could not be obtained directly from the resonant-column tests conducted by the authors. Therefore, those values at $\gamma=10^{-6}$ were estimated by extrapolating the $G-\gamma$ curves as shown in Fig. 5. Shear moduli at $\gamma=10^{-6}$ obtained and the values of $\frac{(2.17-e)^{2}}{1+e} p^{0.38}$. are plotted in full-log scale in Figs. 18 (a) and (b). The power of $p$ was obtained from Figs. 10 (a) and (b) where the value at $\gamma=10^{-6}$ would be estimated to be about 0.38 . From Figs. 18 (a) and (b), it is found that the average curve for sandy soils could be represented by the following equation:

$$
G=900 \frac{(2.17-e)^{2}}{1+e} p^{0.38}
$$

where $G$ is shear modulus $\left(\mathrm{kg} / \mathrm{cm}^{2}\right)$ at $\gamma=10^{-6}$, $e$ means the void ratio and $p$ means the mean principal stress $\left(\mathrm{kg} / \mathrm{cm}^{2}\right)$. 

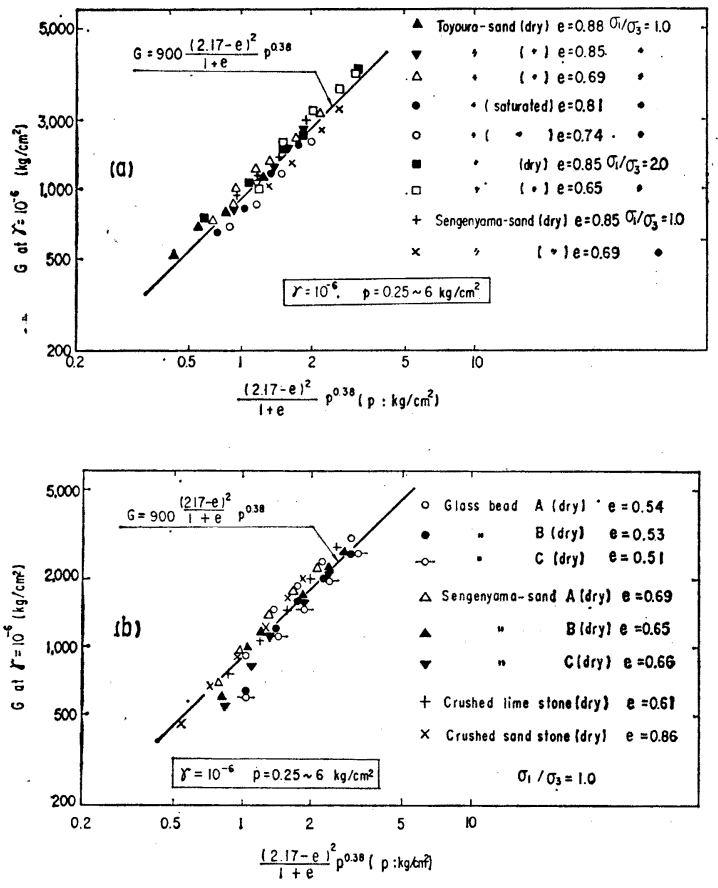

Fig. 18 Shear modulus at $\gamma=10^{-6}$ versus void ratio and mean principal stress.

\subsection{Hysteretic damping coefficient}

As stated before, damping characteristics of the materials tested would be expressed by hysteretic damping coefficients, which could be evaluated from logarithmic decrements if the mechanism of damping in soils is of hysteretic dissipation of energy. A typical test result for air-dry Toyourasand is shown in Fig. 19 where $\Delta_{t}$ means the logarithmic decrement and $\eta$ denotes the hysteretic damping coefficient. This shows that $\eta$ is

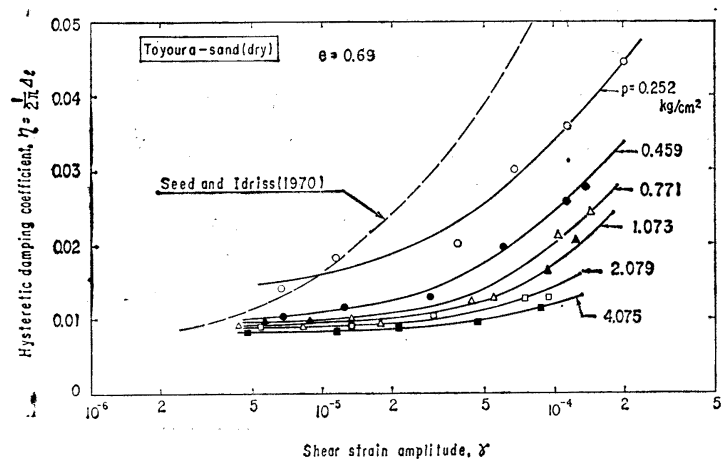

Fig. 19 Hysteretic damping coefficient versus shear strain amplitude of air-dry Toyoura-sand.

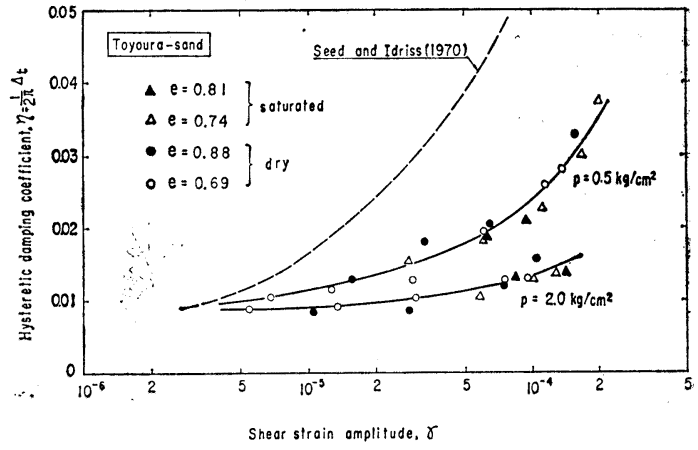

Fig. 20 Hysteretic damping coefficient versus shear strain amplitude of saturated and air-dry Toyoura-sands.

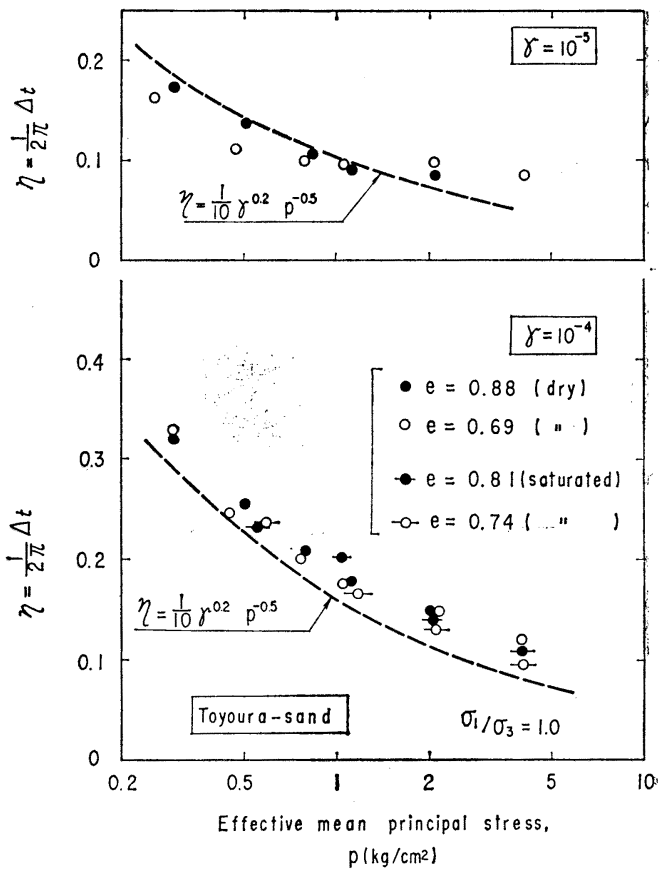

Fig. 21 Hysteretic damping coefficient versus mean principal stress of Toyourasands.

strongly affected by the mean principal stress and the shear strain amplitude. Saturated and air-dry specimens of Toyoura-sand had almost the same value of $\eta$ as shown in Fig. 20. Furthermore, it is found that the change in void ratio does not affect damping capacities of Toyoura-sand and Sengenyama-sand. Meanwhile, Figs. 21,22 and 23 show that the scattering of the values of $\eta$ for different materials is rather larger when comparing with that of $G$. Although it is 


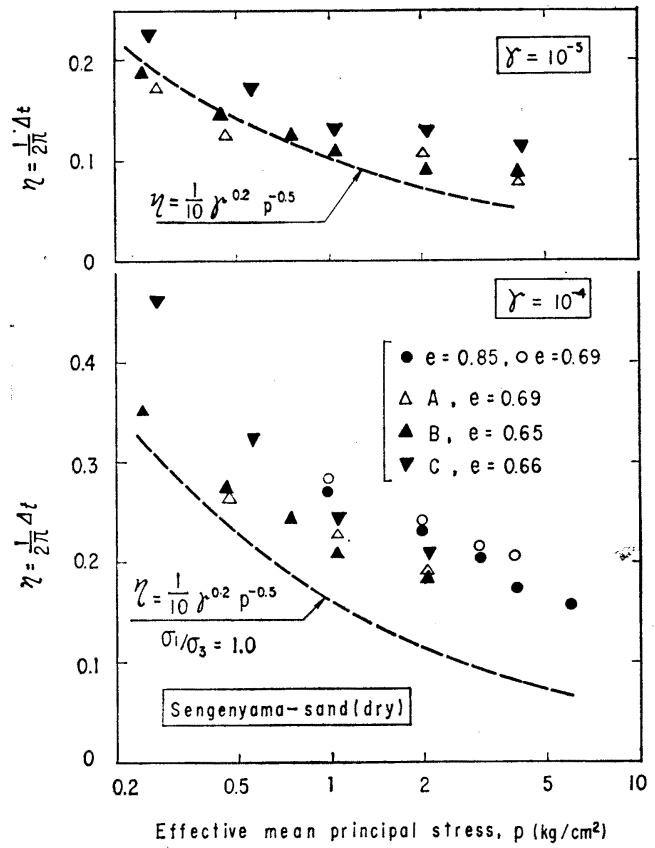

Fig. 22 Hysteretic damping coefficient versus mean principal stress of Sengenyamasands.
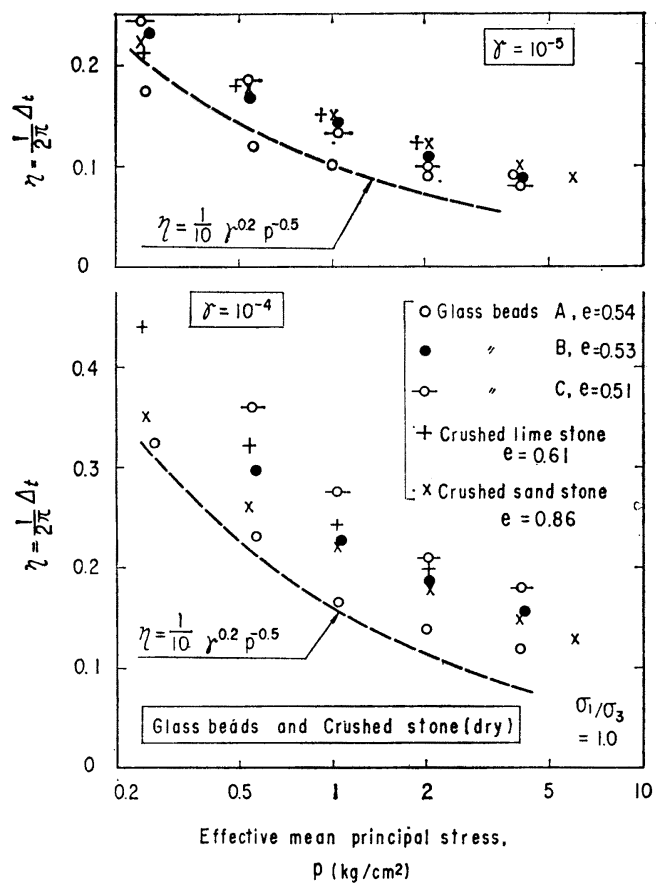

Fig. 23 Hysteretic damping coefficient versus mean principal stress of Glass-beads, Crushed sandstone and Crushed lime-stone. hard to get a conclusion due to this scattering of data, some remarks could be obtained as follows: (1) In any case, $\eta$ increases with increase in shear strain amplitude and with decrease in confining pressure. (2) $\eta$ of Toyourasand have the values almost equal to those of Ottawa-sand, for which $\mathrm{Hardin}^{6)}$ proposed an experimental equation as

$$
r_{0}=\frac{1}{10} \gamma^{0.2} p^{-0.5}
$$

for the range of $\gamma=10^{-6}$ to $10^{-4}$ and $p=0.244$ to $1.46 \mathrm{~kg} / \mathrm{cm}^{2}$ where $r_{0}$ denotes a hysteretic damping coefflcient for Ottawa-sand obtained by dividing logarithmic decrement by $2 \pi$. (3) While the values of $\eta$ of different materials tested could not be represented by such a simple equation as equation (14), all of data could be represented by the following equation:

$$
r_{1}=\gamma_{0}+\Delta \eta
$$

where $\eta$ means hysteretic damping coefficient of respective materials and $\gamma_{0}$ is that of Ottawa-sand expressed in eq. (14) and $\Delta \eta$ is a constant which is not affected by $p$, void ratio and shear strain amplitude $\Delta \eta$ has a different values for different materials.

\section{CONCLUSIONS}

A procedure using a resonant-column apparatus developed in the present study would be one of the most effective ways to evaluate shear moduli and damping characteristics of soils. The following remarks would be concluded from the extensive resonant-column tests conducted.

(1) By testing materials without fine particles it is found that the equation (10) expresses the experimental results of shear moduli at $\gamma=10^{-4}$ and equation (13) fits with those at $\gamma=10^{-6}$. For materials tested, water content, grading, particle shape and grain size have little effects on shear moduli of the value around $10^{-6} \sim 10^{-4}$ of the shear strain.

(2) While the value of mean principal stress is kept constant, shear moduli and logarithmic decrements are nearly constant irrespectively of the value of shear stress up to the stress ratio $q / p$ of a certain value, say 1.0. However, beyond this value of $q / p$, shear modulus starts to decrease and logarithmic decrement starts to increase with increase in $q / p$. The decreased shear moduli and the increased logarithmic decrements do not completely recover after unloading.

(3) The decreasing rate of shear moduli with increase in shear strain amplitudes has larger 
value for the smaller value of the mean principal stress.

(4) Damping capacities decrease with increase in $p$ and increase with increase in shear strain amplitudes. However, damping capacities are not affected by the change in void ratios under constant values of the other parameters. For Toyoura-sand, water content has little effect on damping capacities. Damping values of various materials could be represented by eqs. (14) and (15).

\section{ACKNOWLEDGEMENTS}

This research was strongly supported by Dr. T. Okubo, Head of Structure and Bridge Division, Public Works Research Institude. Comprehensive tests were conducted with an assistance of $\mathrm{Mr}$. S. Yoshida, Earthquake Engineering Research Section, Public Works Research Institute and Mr. Y. Fukutome, an undergraduate student of Chiba Institute of Technology. The authors wish to acknowledge their cooperations.

\section{REFERENCES}

1) Iida, K.: The Velocity of Elastic Waves in Sand, Bull. Earthquake Res. Inst. 16, Earth. quake Research Institute, Tokyo University, 1938.

2) Richart, F. E., Jr., J. R. Hall, Jr. and R. D. Woods: Vibrations of Soils and Foundations, Prentice-Hall Inc., 1970.

3) Hardin, B. O. and J. Music: Apparatus for Vibration of Soil Specimens During the Triaxial Test, ASTM, STP, No. 392, 1965.

4) Drnevich, V. P.: Effect of Strain History on the Dynamic Properties of Sand, Ph. D. Dissertation, Univ. of Michigan, 1967.

5) Lazan, B. T.: Damping of Materials and Members in Structural Mechanics, Pergamon Press, Oxford, London, 1968.

6) Hardin, B. O.: The Nature of Damping in Sands, J. of S.M.F.E., Proc. ASCE, Vol. 91, No. SM1, Jan., 1965.

7) Hardin, B. O. and W. L. Black: Sand Stiffness Under Various Triaxial Stresses, J. of ASCE, Vol. 92, No. SM2, 1966.

8) Seed, H. B. and I. M. Idriss: Soil Moduli and Damping Factors for Dynamic Response Analysis, Report No. EERC70-10, Dec., 1970, College of Eng., Univ. of California, Berkeley, 1970 .

(Received March 10, 1975) 